\title{
A escola contribuindo para melhores práticas no setor produtivo local
}

Área Temática Meio Ambiente

\author{
Paulo de Tarso da Cunha Chaves ${ }^{1}$ \\ Maicon Fernandes ${ }^{2}$ \\ Beatriz Ern da Silveira ${ }^{3}$ \\ Francieli Azeredo 4 \\ Luciane Hulyk ${ }^{5}$ \\ Maíra Afonso 6 \\ Ediumar Nakalski ${ }^{7}$
}

\section{RESUMO}

O extravio de petrechos de pesca - redes, anzóis, flutuadores, chumbos, atratores luminosos, reservatórios de combustível, etc. - é, no mundo atual, um sério agente de poluição dos mares e rios, além de fonte para prejuízos econômicos. Isso decorre da perda do material, em si, e do risco de ele originar pesca fantasma - a captura cumulativa de peixes, crustáceos e outros recursos pesqueiros que dessa forma deixam de ser acessados pelo homem, por exemplo: um pedaço de rede que, submerso, continua pescando por muitos meses, até que se decomponha ou seja carreado à praia. 0 assunto foi pela primeira vez abordado no Brasil em um projeto de pesquisa financiado pelo CNPq e executado de 2010 a 2012 por uma equipe UFPR. Neste ano o mesmo projeto distribuiu ao público leigo 2.000 exemplares impressos que alertam sobre os riscos ambientais e econômicos do extravio desses petrechos, muitas vezes decorrente de práticas pesqueiras inadequadas.

PALAVRAS-CHAVE: Pesca. Práticas Pesqueiras. Extravio. Petrechos.

\section{Objetivos}

No presente projeto de extensão, implantado em 2013, a equipe UFPR objetiva interagir com jovens estudantes, para que desenvolvam conhecimento e gosto pela pesquisa aplicada à resolução de um problema inerente ao setor produtivo de sua comunidade. Seus objetivos específicos são: transmitir e receber conhecimentos locais sobre causas, ocorrências e consequências do extravio de petrechos de pesca; fomentar

\footnotetext{
${ }^{1}$ Departamento de Zoologia, Universidade Federal do Paraná.

2 Departamento de Zoologia, Universidade Federal do Paraná.

${ }^{3}$ Bolsista CNPq.

${ }^{4}$ Acadêmicas do Curso de Ciências Biológicas da UFPR.

${ }^{5}$ Acadêmicas do Curso de Ciências Biológicas da UFPR.

${ }^{6}$ Acadêmicas do Curso de Ciências Biológicas da UFPR.

${ }^{7}$ Professor da Escola Dom Gregório Warmeling, SC.
} 
pesquisa sobre extravio de petrechos de pesca e redução de danos econômicos e ambientais; disponibilizar à comunidade-alvo conhecimento sobre extravio de petrechos de pesca e medidas mitigadoras; documentar, junto aos órgãos públicos e de gestão de recursos pesqueiros, subsídios sobre extravio de petrechos de pesca e apresentar recomendações; promover nos estudantes da comunidade-alvo técnicas e gosto por pesquisa em Ciência, Tecnologia e Inovação (CT\&I) e difusão dos resultados; promover nos acadêmicos da UFPR a aplicação de conhecimentos de Biologia e Licenciatura junto a estudantes e professores de escolas parceiras. Tal processo educativo é favorecido por esses estudantes serem parentes e vizinhos de pescadores e, alguns deles, futuros pescadores. 0 projeto de extensão busca, então, engajamento de estudantes de escolas como potenciais educadores de boas práticas pesqueiras. 0 projeto inicia os participantes em práticas de pesquisa em CT\&I, como, por exemplo, identificação in situ de outras fontes de extravio - que não as já reconhecidas pelo projeto de pesquisa; estimativa dos prejuízos ambientais, econômicos ou de outra natureza que os extravios vêm causando em seu município; e desenvolvimento de processos e materiais que possam ajudar na redução, seja do extravio, seja de suas consequências. Além dos benefícios à comunidade por melhores práticas pesqueiras que os moradores profissionais da pesca - passem a empregar, o projeto propicia que os estudantes se reconheçam atores de um processo construtivo em tema altamente identificado com o dia a dia de seu município.

\section{Por que com estudantes de Balneário Barra do Sul/SC}

0 ambiente escolar é adequado às ações de caráter educativo, científico e tecnológico que são realizadas. Educativo, porquanto os estudantes da escola vêm sendo propagadores da importância de se evitarem extravios de petrechos pelos pescadores profissionais e amadores; científico, porque com a orientação de seus professores e da equipe UFPR do projeto, eles exercitam o processo investigativo da avaliação de extravios de petrechos de pesca no município: levantamento de ocorrência, identificação dos agentes causais, avaliação das consequências, proposição de medidas mitigadoras, discussão, difusão; e tecnológico, porque, entre as medidas mitigadoras de possível proposição, algumas referem-se à constituição e ao uso dos petrechos. No primeiro 
semestre 2013, o público-alvo vem sendo de estudantes dos ensinos fundamental e médio da Escola de Ensino Básico Dom Gregório Warmeling, de Balneário Barra do Sul/SC. Em agosto, porém, a avaliação será realizada com a equipe do projeto, os professores da escola e os alunos participantes, para que, a partir do segundo semestre, seja conveniente que outras escolas se engajem.

Dos seis municípios estudados pelo Projeto de Pesquisa CNPq 2010-2012, Balneário Barra do Sul é o de mais intensa atividade pesqueira, é forte na pesca marítima amadora, e o maior centro de pesca profissional artesanal do norte catarinense. 0 município possui uma Secretaria de Agricultura e Pesca e uma unidade da Epagri - a entidade extensionista do Estado. Esses dois órgãos públicos são potenciais colaboradores no apoio aos estudantes parceiros e na difusão e aplicação dos resultados do projeto. Assim como outros municípios litorâneos de pequeno porte, as escolas recebem jovens que têm quotidiana interação com os profissionais da pesca, sendo parentes ou vizinhos de pescadores profissionais e de guias da pesca amadora; têm fácil acesso às praias onde ocorrem os petrechos de pesca extraviados; e são, alguns deles, futuros profissionais da pesca.

A parceria do projeto com a EEB Dom Gregório Warmeling atende às perspectivas de impacto e transformação - os estudantes da escola são alertados e instruídos sobre os danos causados por práticas inadequadas em sua comunidade, sentindo-se agentes para introdução de novos materiais e processos nos meios produtivos locais; interação dialógica - estudantes e professores parceiros exercitam a pesquisa no campo e exploram formas de sistematizar as informações, compartilhando-as com os coordenadores e estudantes da UFPR, produzindo juntos conclusões e recomendações sobre causas, consequências e medidas mitigatórias; interdisciplinaridade - pois os procedimentos empregados requerem orientação pedagógica, conhecimentos das técnicas pesqueiras praticadas no município, conhecimentos biológicos e sobre o ambiente e conhecimento dos materiais de pesca. Adicionalmente, a apresentação dos trabalhos nos eventos programados e a produção de relatórios requerem desenvolvimento de técnicas transversais, especialmente quanto à produção de material expositivo, ao relato oral de um trabalho de pesquisa e à redação técnico-científica; e, pelo acima exposto, indissociabilidade ensino-pesquisa-extensão. Os coordenadores e os alunos UFPR, por sua vez, encontram no projeto um ambiente ideal para 
compartilhar resultados de pesquisa já realizada na própria região; recolher informações até então desconhecidas, fruto da pesquisa in situ realizada pelos alunos locais; promover a apropriação de conhecimento pela comunidade-alvo; despertar nos jovens o gosto pela formulação de questões inerentes ao dia a dia dessa comunidade, de métodos para respondê-las, de procedimentos para transferir conhecimento aos seus concidadãos, e de trabalho compartilhado para buscar soluções práticas e eficazes. Acrescenta-se a importância na formação dos alunos UFPR: os acadêmicos que participam do projeto, bolsistas e não-bolsistas, são do Curso de Ciências Biológicas; portanto, potenciais professores e pesquisadores. A interação com os estudantes e professores da escola parceira permite-lhes desenvolverem práticas de licenciatura e apropriação do conhecimento, e o objeto da pesquisa favorece o desenvolvimento de monografias de bacharelado.

\section{Métodos}

De janeiro a março 2013, foram engajados acadêmicos colaboradores da UFPR, mediante divulgação junto à Coordenação do Curso de Ciências Biológicas. Em março ministrou-se palestra sobre o projeto aos estudantes e professores da Escola Dom Gregório Warmeling: motivação, objetivos, métodos; distribuição dos impressos já produzidos pelo projeto de pesquisa. Foram então cadastrados estudantes e professores parceiros. De abril a junho realizaram-se dinâmicas presenciais na escola, a cada 15 dias, para instrução sobre materiais de pesca que podem ser extraviados (Figura 1), as causas e consequências de tal extravio, e discussão sobre medidas de redução dos extravios. Cadernetas de observações e de entrevistas foram distribuídas aos grupos de alunos, para que registrassem seus apontamentos. Houve sistematização dos dados e informações obtidos pelos alunos e discussão. 


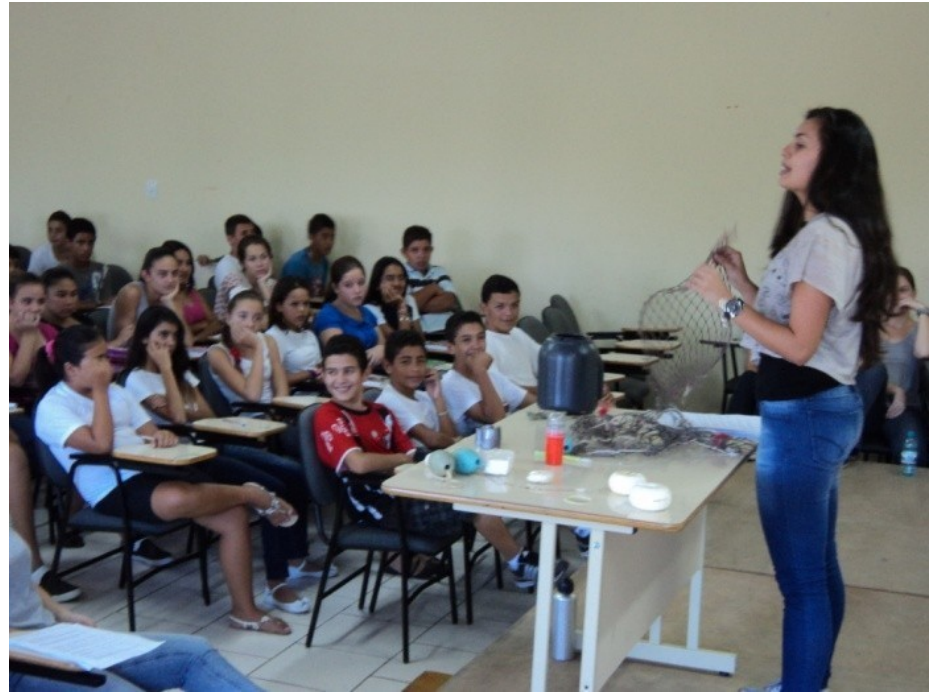

Figura 1: Acadêmica da UFPR orienta os alunos da escola parceira, em Balneário Barra do Sul/SC, uma das dinâmicas de instrução sobre materiais comumente extraviados pela atividade pesqueira.

\section{Resultados}

Na etapa 2013/1, atuaram 80 alunos voluntários da escola parceira, mais um professor - coautor do presente trabalho -, além da equipe UFPR. Os alunos relataram observações de petrechos de pesca (cerca de 70, a maioria danificada) encontrados nas praias e entrevistas (45) com pescadores. Os extravios mais mencionados pelos pescadores foram de linhas, anzóis, boias, redes e objetos plásticos; as causas mais indicadas, colisões com barcos maiores e pedras; e o prejuízo, o financeiro, poucos atentando para implicações ambientais.

Em junho forma preparados 15 banners resumindo os trabalhos dos grupos, e, em 4 de julho, foi realizada uma exposição na escola, aberta à comunidade (Figura 2), a qual 
recebeu visitantes notadamente internos à escola, quais sejam, alunos e professores. Apesar da divulgação mediante 3.000 flyers, poucas pessoas externas à escola prestigiaram o evento. A última atividade dessa primeira etapa do projeto foi realizada em agosto, constando da avaliação do trabalho pelos alunos, professores e Direção da escola e pela equipe UFPR. Por recurso financeiro obtido junto ao Fundo de Desenvolvimento Acadêmico da UFPR, obtiveram-se (i) impressão dos banners,

(ii) outros materiais de apoio, (iii) livros da Editora da Universidade, que serão doados à biblioteca da escola; e (iv) pen-drives, que serão doados ao professor parceiro e, mediante sorteio, aos alunos participantes.

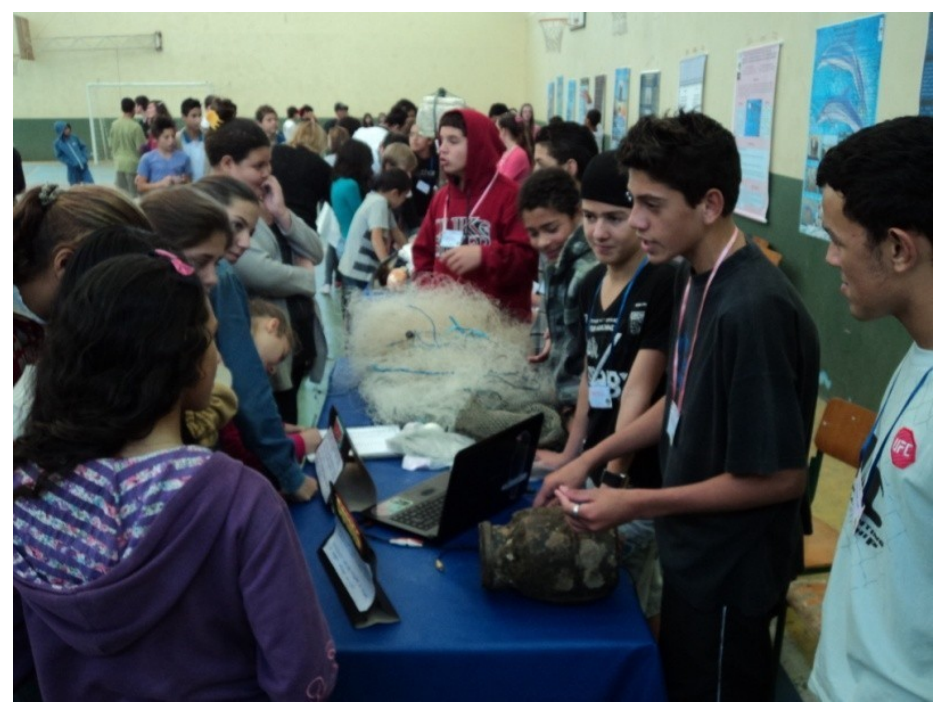

Figura 2: Exposição organizada na escola parceira: apresentam-se materiais de pesca encontrados nas praias do município e discutem-se, quanto aos extravios, (i) causas, (ii) consequências e (iii) recomendações para reduzi-los.

\section{Avaliação e perspectiva}

Em agosto esta etapa finalizou com a avaliação do projeto pelos alunos e seu professor. A avaliação preliminar e informal é muito positiva, pois os alunos da escola desenvolveram conteúdo, métodos, e a equipe UFPR alcançou a interação dialógica tencionada. No segundo semestre, o projeto poderá repetir a ação com outros alunos da escola ou deslocar-se a São Francisco do Sul, atendendo convite já formulado pela Secretaria de Agricultura e Pesca. 